\title{
Human adipose tissue-derived mesenchymal stem cells in Parkinson's disease冈lnhibit Thelper 17 cell differentiation and regulate immune balance towards a regulatory $T$ cell phenotype
}

\section{Yong Bi}

Shanghai No.4 People's Hospital affiliated to Tongji University School of Medicine

Huazheng Liang

Tongji University https://orcid.org/0000-0001-9097-7357

Xiaobin Lin

The First Affiliated Hospital of Wenzhou Medical University

\section{Dehao Yang}

The First Affiliated Hospital of Wenzhou Medical University

\section{Xiaowei Zhang}

The First Affiliated Hospital of Wenzhou Medical University

Jianming Ke

The First Affiliated Hospital of Wenzhou Medical University

\section{Jingjing Xiao}

Shanghai Fourth People's Hospital affiliated to Tongji University School of Medicine

\section{Zhilin Chen}

Shanghai Fourth People's Hospital affiliated to Tongji University School of Medicine

\section{Weian Chen}

The First Affiliated Hospital of Wenzhou Medical University

\section{Xu Zhang}

The First Affiliated Hospital of Wenzhou Medical University

\section{Shaoshi Wang}

Shanghai Fourth People's Hospital affiliated to Tongji University School of Medicine Chun-Feng Liu ( $\square$ liuchunfeng@suda.edu.cn )

\section{Research}

Keywords: Parkinson's disease, adipose-derived mesenchymal stem cells, CD4+T cell, T helper 17 cell, T regulatory cell, peripheral blood mononuclear cells, leukemia inhibitory factor 
DOI: https://doi.org/10.21203/rs.2.21813/v1

License: (c) (1) This work is licensed under a Creative Commons Attribution 4.0 International License. Read Full License 


\section{Abstract}

Parkinson's disease (PD), known as a neurodegenerative disorder, shows typical pathology of neuroinflammation, which might be the result of the imbalance between regulatory $T$ cells (Treg) and $T$ helper 17 (Th17) cells. The present study aimed to investigate the modulating effect of Ad-MSCs on peripheral blood mononuclear cells (PBMCs) derived from PD patients. CD4 + peripheral blood T cells were isolated and co-cultured with Ad-MSCs at a ratio of 4:1 under Th17 or Treg polarizing conditions, respectively, for 4 days. Our results showed that Ad-MSCs specifically inhibited the differentiation of IL17-producing CD4 + T cells collected from PBMCs of PD patients evidenced by the decreased expression of RORyt- the key transcription factor for Th17 cells, IL-6R, and IL-23R. In the meantime, Ad-MSCs and induced a functional CD $4+$ CD25 + Foxp3 + T regulatory cell phenotype evidenced by the secretion of IL10. Furthermore, levels of LIF protein and its receptor mRNA were significantly increased under both polarizing conditions. These findings suggest that the regulation of the Th17/Treg balance by Ad-MSCs was correlated with the increase in LIF secretion. Therefore, Ad-MSCs are an important player in modulating inflammatory responses and a potential therapeutics for PD patients.

\section{Introduction}

Parkinson's disease (PD) is a chronic neurodegenerative disorder characterized by progressive loss of dopaminergic neurons due to Lewy pathology and the presence of an active inflammatory response, which leads to classical motor and non-motor symptoms [1, 2]. Growing evidence has indicated that $T$ helper cells might contribute to the cascade of neuroinflammation by breaking the balance of peripheral T helper 17 (Thl7) cells and regulatory T (Treg) cells [3-9]. IL-17-producing Th17 cells play a pivotal role in neuronal cell death, whereas Treg cells attenuate Th17 cells mediated nigrostriatal dopaminergic neuronal cell death [10-12]. As a result, imbalance between Th17 and Treg cells leads to neurodegeneration in the substantia nigra.

An increased number of T lymphocytes have been found in postmortem brain tissue of PD patients and an increased number of Th17 cells in their peripheral blood [4-8]. Similar findings were found in mice intoxicated with MPTP [11-14]. The increased number of Th17 cells in the blood was correlated with augmented cell death of human induced pluripotent stem cell (hiPSC)-derived midbrain neurons from PD patients [10]. In contrast, Treg cells attenuated inflammatory responses, microglial activation, and protected dopaminergic neurons from MPTP intoxication $[12,15,16]$. In the blood of PD patients, there is a decreased number or dysfunction of Treg cells, leading to the imbalance in immune responses [6, 1720]. These suggest that the deviated balance between Th17 and Treg cells may play critical roles in adaptive immunity mediated PD pathogenesis.

Th17 cells are characterized by expression of the transcription factor RORyt and secretion of IL-17 [21]. Their pathogenicity is counteracted by Foxp $3^{+}$Treg cells which are characterized by expression of the transcription factor Foxp3 and secretion of IL-10 [22]. In the presence of IL- 6 and TGF- $\beta$, CD4 ${ }^{+} T$ cells increase its expression of IL-23R and RORyt which suppresses the expression of Foxp3 $[22,23]$ and the 
production of IL-10 [23]. This results in an increased number of Th17 cells and a decreased number of Treg cells [22-24].

AD-MSCs are one of the most promising candidates due to the easy access to autologous adipose tissue, its abundance, proliferation and differentiation potential, and its immunoregulatory capacities to suppress inflammatory responses $[25,26]$. Therefore, they have been used to regulate immune responses in various conditions [27-30]. One of the underlying mechanisms is that it induces Treg cells and suppresses Th17 cell differentiation [9, 12, 20, 29-31]. This might be applied to the management of PD.

Our previous study on MS has shown that Ad-MSCs alleviated inflammatory responses through the abovementioned mechanism by specifically secreting LIF [32,33]. However, it is still unclear whether ADMSCs can induce $\mathrm{CD} 4^{+} \mathrm{T}$ cells to Treg cells and regulate immune responses in PD patients. Therefore, the present study aimed to investigate the influence of Ad-MSCs on PBMCs of PD patients, focusing on the differentiation of $\mathrm{CD} 4^{+} \mathrm{T}$ cells and expression of relevant transcription factors as well as cytokines.

\section{Materials And Methods}

\subsection{Isolation, culture, and identification of human MSCs}

Adipose tissue was obtained from 7 female patients (aging 22-35) undergoing plastic surgery in the Department of Plastic Surgery of the First Affiliated Hospital of Wenzhou Medical University. Subjects were enrolled after excluding infectious diseases, autoimmune disorders, and other severe medical conditions. Briefly, the adipose tissue was sliced for culture in the LG-DMEM medium (HyClone, Logan, Utah, USA) $+10 \%$ FBS (Gibco) and 1\% penicillin/streptomycin (Solarbio, Beijing, China) at $37{ }^{\circ} \mathrm{C}$ with $5 \%$ $\mathrm{CO}_{2}$ and $95 \%$ air for $72 \mathrm{~h}$. After 5-7 days, migrated spindle-shaped Ad-MSCs were found on the bottom of culture flask. Cells were passaged once $80 \%$ confluence was achieved. Cell surface markers were assessed using flow cytometry. Ad-MSCs expressed CD44, CD29, CD73, CD105, CD13, and partially CD49, but not CD31, CD34, and HLA-DR, which was consistent with our previous results [32, 33]. These results suggested that the cultured cells were actually Ad-MSCs.

\subsection{Isolation and co-culture of $\mathrm{CD}^{+}{ }^{+} \mathrm{T}$ cells with Ad-MSCs}

$\mathrm{CD}^{+} \mathrm{T}$ cells (purity 95\%) were isolated from freshly collected peripheral blood of six PD patients in the Department of Neurology, The First Affiliated Hospital of Wenzhou Medical University who met the diagnostic criteria of PD (UK brain bank) [2] using a CD4 ${ }^{+} \mathrm{T}$ cell isolation kit (Miltenyi Biotech, Cat No.130094-131). Anti-CD4-PE-cy5.5 was added to the final cell suspension and an appropriate column and sorter were selected for flow cytometry. $C D 4^{+} T$ cells were stimulated with a CD3/CD28 antibody to proliferate

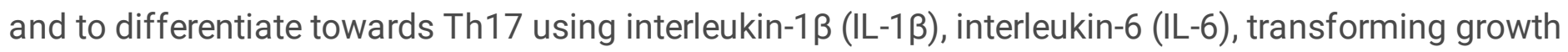
factor- $\beta$ (TGF- $\beta$ ), interleukin-23 (IL-23). Polarization of Treg cells: add CD $4^{+}$T cells to the culture plate which has been coated with $2 \mathrm{ug} / \mathrm{ml}$ anti-CD3. Add soluble anti-CD28 $(1 \mathrm{ug} / \mathrm{ml})$ and cytokines such as TGF- $\beta(2.5 \mathrm{ng} / \mathrm{ml}), \mathrm{IL}-2(20 \mathrm{ng} / \mathrm{ml})$ to the culture plate and incubate for 4 days to induce cell 
differentiation towards Treg. They were then co-cultured with Ad-MSCs at a ratio of 1:4 from the 3rd to 5th passage for 4 days and the supernatant was collected for ELISA and cells for flow cytometry.

\subsection{Quantitative real-time-polymerase chain reaction (RT- PCR)}

Total RNA was extracted from cultured cells using Trizol. After measuring its concentration and purity, $1 \mu \mathrm{g}$ RNA was used for reverse transcription to produce cDNA. The latter was added to the SYBR Green mix for real-time PCR reaction (Table 1). PCR reaction was completed in a final volume of $20 \mu \mathrm{l}$ containing $1 \mu \mathrm{l}$ of the cDNA product, $1 \mu \mathrm{l}$ upstream primer, $1 \mu \mathrm{l}$ downstream primer, $\mathrm{ddd}_{2} \mathrm{O} 7 \mu \mathrm{l}$, and $10 \mu \mathrm{l}$ 2x Master mix. PCR amplification products were analyzed using the software of the Applied Biosystems 7500 Real-time PCR system. Expression levels of RORyt, IL-6R, IL-23R, LIF, LIFR were compared between groups after normalizing their levels with the level of a house keeping gene.

Table 1

The sequence of the primers for qRT-PCR

\begin{tabular}{|c|c|}
\hline Gene & The primer sequence $\left(5^{\prime}-3^{\prime}\right)$ \\
\hline ROR & $\begin{array}{l}\text { Forward: TGTCCCGAGATGCTGTCAAGT } \\
\text { Reverse: GAGGGGTCTTGACACTGGTT }\end{array}$ \\
\hline GAPDH & $\begin{array}{l}\text { Forward: GCCAGTAGACTCCACGACAT } \\
\text { Reverse: GCAAGTTCAACGGCACAG }\end{array}$ \\
\hline LIFR & $\begin{array}{l}\text { Forward: CCCCAAATAATGTTGAGGTTCTG } \\
\text { Reverse: CTGCGGCTGGGTTTGGTAT }\end{array}$ \\
\hline IL-6R & $\begin{array}{l}\text { Forward: CCTGCCAACATCACAGTCACTG } \\
\text { Reverse: CAGCCCGATATCTGAGCTCAA }\end{array}$ \\
\hline IL-23R & $\begin{array}{l}\text { Forward: CAAGAAACAGGCAAAAGGTA } \\
\text { Reverse: ATGTGACCTGGGGAACTGT }\end{array}$ \\
\hline LIF & $\begin{array}{l}\text { Forward: CAGCATCACTGAATCACAGAGC } \\
\text { Reverse: AGTATGAAACATCCCCACAGGG }\end{array}$ \\
\hline
\end{tabular}

Supernatant of cultured cells was collected and levels of LIF,IL-6, IL-23, IL-17A, IL-10 and TGF- $\beta$ were measured in triplicates by following the protocol provided by the manufacturer. The OD value was measured at the wavelength of $450 \mathrm{~nm}$. Absorbance readings were then converted to concentrations of target proteins. A standard curve was constructed and concentrations of samples were calculated.

\subsection{Statistical analysis}

Data were analyzed using the t-test for parametric data or Mann-Whitney $U$ test for non-parametric data. We performed statistical analyses with SPSS 25.0 software (SPSS, Chicago, IL, USA) and GraphPad 
Prism 8.0 (GraphPad Software, San Diego, CA, USA); $p<0.05$ was considered significant. Data were presented as the means \pm standard error of means.

\section{Results}

\subsection{Demographic information of PD Patients}

Six PD patients were enrolled to collect PBMCs for co-cultured experiments. The clinical features of the PD patients were listed in Table 2.

Table 2

Clinical features of PD patients

\begin{tabular}{|ll|}
\hline PD patients & \\
\hline Number & 6 \\
\hline Gender (male/female) & $4 / 2$ \\
\hline Age (years) & $44-75$ (mean 64.83) \\
\hline Disease duration (years) & $\begin{array}{l}1-8 \text { (mean 4.28) } \\
\text { NA }\end{array}$ \\
\hline UPDRS score & 8-20 (mean 12.33) \\
\hline
\end{tabular}

\subsection{Ad-MSCs inhibited the differentiation of CD4 ${ }^{+} \mathrm{T}$ cells into Th17 cells}

The influence of Ad-MSCs on the differentiation of $C D 4^{+} T$ cells of PD patients was analyzed in vitro. When IL-1 $\beta$, IL-6, TGF- $\beta$ (10 ng/mL), IL-23 (40 ng/mL), anti-CD3, and anti-CD $28 \mathrm{mAbs}$ were added, CD $4^{+}$T cells were induced to differentiate into IL-17-producing Th17 cells. After 4 days co-culture with Ad-MSCs, the proportion of IL-17 ${ }^{+} \mathrm{CD} 4^{+}$Th17 cells decreased significantly compared with that of the control group (Fig. 1A,B). Meanwhile, the expression of RORyt, a Th17 specific transcription factor, was decreased significantly in the presence of Ad-MSCs. (Fig. 1C).

\subsection{Ad-MSCs suppressed the expression of IL-6R and IL- 23R}

Decreased expression of IL-6R and IL-23R mRNA was observed when CD4 ${ }^{+}$T cells were co-cultured with Ad-MSCs under the Th17 polarizing condition (Fig. 2A,2B), and decreased expression of IL-6R mRNA under the Treg polarizing condition (Fig. 2C). However, no significant differences in the production of IL-6, IL-23 and TGF- $\beta$ were found when compared with non-MSCs treated T cells (Fig. 2D-F). These results suggested that Ad-MSCs might inhibit the differentiation of Th17 cells by down-regulating the expression of RORyt mRNA, IL-6R and IL-23R. 


\subsection{Ad-MSCs induced $\mathrm{CD}^{+}{ }^{+} \mathrm{T}$ cells to a functional Treg phenotype}

It was found that $\mathrm{CD} 4^{+} \mathrm{CD} 25^{+} \mathrm{Foxp} 3^{+} \mathrm{T}$ cells were slightly increased after stimulating with anti-CD3/CD28 Abs, but increased significantly under the Treg polarizing condition with the addition of Ad-MSCs (Fig. 3A,B). Furthermore, addition of Ad-MSCs markedly suppressed the expression of IL-6R mRNA (Fig. 2C). As expected, when Ad-MSCs were added to the culture on day 4, a significant increase in the production of IL-10 was observed in comparison with the non-MSC treated culture (Fig. 3C). Therefore, Ad-MSCs showed the capability of inducing $\mathrm{CD} 4^{+} \mathrm{T}$ cells to functional Treg cells and suppressing the induction to Th17 cells on day 4 under polarizing conditions.

\subsection{LIF is the key factor of the inhibitory effect}

LIF, an important cytokine secreted by stem cells, plays an anti-inflammatory role [34,35]. To determine whether LIF, secreted by Ad-MSCs, is associated with the acquired immunosuppressive activity, the level of LIF was analyzed. We found a significant increase in its level when Ad-MSCs were present than when T cells were cultured alone under either the Th17 and Treg polarizing condition (Fig. 4A,D). Consistent with the increased production of LIF produced by Ad-MSCs, increased expression level of LIF mRNA was also observed (Fig. 4B,E). As expected, expression of LIFR mRNA was increased under both Th17 and Treg polarizing conditions (Fig. 4C,F). These results suggested that LIF might play a critical role role in AdMSCs suppressing Th17 cell differentiation, promoting Treg differentiation, increasing the expression of LIFR mRNA and suppressing the expression of IL-6R mRNA (Fig. 2A,C). These were further supported by the increased expression level of RORyt, the key transcription factor of Th17 cells, after adding a neutralizing antibody of LIF, and the increased percentage of IL- $17^{+} \mathrm{CD} 4^{+} \mathrm{Th} 17$ cells (our previous results) [32].

\section{Discussion}

Human Ad-MSCs possess extraordinary properties of attenuating effector T cell responses, which have been demonstrated in diverse immune disorders. The present study found that human Ad-MSCs specifically inhibited IL-17-producing $\mathrm{CD} 4^{+} \mathrm{T}$ cell differentiation under the Th17 polarizing condition, which was accompanied by suppressing the expression of the transcription factor RORyt. They induced a functional $\mathrm{CD} 4^{+} \mathrm{CD} 25^{+} \mathrm{Foxp}^{+}$Treg cell phenotype evidenced by the secretion of IL-10 under the Treg polarizing condition. These findings are in accordance with expectations of a large number of studies searching for innovative therapeutics for PD patients $[12,20,31,36-38]$.

Treg abnormalities in PD patients have been shown either by its reduced number or by its functional deficit $[5,6,18,20]$. This might be due to the increased number of Th17 cells as well as the increased secretion of IL-17 in the serum of PD patients. Blockage of IL-17 or neutralizing it with an IL-17 antibody rescued neuronal death $[6,7,9-11]$. Animal studies have revealed that an increased number of Th17 cells 
lead to tissue damage by producing a neurotoxic cytokine-interleukin IL-17[11-14, 39], which is attenuated by Treg cells [12]. Animal studies and clinical trials have demonstrated that Ad-MSCs are a potential therapeutic strategy due to their capability of suppressing Th17 responses and inducing functional Treg cells [25-30, 40-42]. Based on this, it was postulated that Ad-MSCs would modulate immune responses in PD patients in the same way as it did in animals. We found that Ad-MSCs inhibited the differentiation of peripheral $\mathrm{CD} 4^{+} \mathrm{T}$ cells into Th17 cells and induced their differentiation into functional Treg cells evidenced by the secretion of IL-10. Our results confirmed the hypothesis and demonstrated the beneficial role of Ad-MSCs in regulating immune responses in vitro.

Based on our previous findings that Ad-MSCs mediated immunosuppression of Th17 in MS patients and a mouse model of MS [32,33], we hypothesized that LIF was the key player in mediating the suppression of Th17 cell differentiation. In the co-cultured Ad-MSCs-CD4 ${ }^{+}$T cell experiment, we found that Ad-MSCs accelerated the differentiation of $\mathrm{CD}^{+}{ }^{+} \mathrm{T}$ cells towards Treg, evidenced by the increased secretion of IL10, and suppressed differentiation towards IL-17-secreting Th17 cells, which was supported by the decreased expression of RORyt. We also found that LIF protein was significantly increased when CD4 ${ }^{+} \mathrm{T}$ cells were co-cultured with Ad-MSCs than when T cells were cultured alone under both Th17 and Treg polarizing conditions. In line with the increased protein level, the level of LIFR mRNA was also increased. Furthermore, expression of LIFR mRNA was increased under both Th17 and Treg polarizing conditions.

Both IL-23R and IL-6R are involved in the signaling pathways that lead to Th17 cell differentiation [2123]. Consistent with our hypothesis, levels of IL-6R mRNA were downregulated under both Th17 and Treg polarizing conditions, and IL-23R mRNA was decreased under the Th17 polarizing condition. This was supported by the increased expression of RORyt and IL-6R mRNA after neutralizing LIF with an antibody as shown in our previous study [32]. These suggest that LIF is the key mediator of this process, which is in line with previous findings in that TGF- $\beta$ and PGE2 are involved in Treg upregulation and Th17 downregulation in humans [43].

LIF belongs to the IL-6-type cytokine family and it is important for T-cell maturation. It is different from IL6 in that it binds to gp130/gp190 hetero-dimers, whereas IL-6 binds to gp130 homodimers [44]. Gp130, therefore, is the shared subunit of cytokine receptors of the IL- 6 family. IL- 6 is known to inhibit the expression of the LIFR subunit, opposing the physiological effect of LIF $[44,45]$. This might be the explanation for the increased LIFR level observed in our study.

LIF suppresses expression of Th17 specific genes such as the transcription factor RORyt, and simultaneously increases expression of a Treg specific transcription factor-Foxp3 [34, 35, 45]. In contrast, IL-6 decreased the level of Foxp3 and increased the level of RORyt [21, 45]. Therefore, LIF/IL-6 balance is critical for T-cell lineage maturation [44]. These results suggest that LIF, in combination with IL-6 signal pathway blockers, might become promising therapeutics for PD and other immune disorders [35] though the underlying mechanism remains largely unknown. 
In conclusion, human Ad-MSCs suppress the differentiation of $\mathrm{CD} 4^{+} \mathrm{T}$ cells isolated from PD patients into Th17 cells in vitro. This suppressive effect was mainly associated with an increase in functional $\mathrm{CD} 4^{+} \mathrm{CD} 25^{+} \mathrm{Foxp}^{+}$Treg cells and IL-10 secretion. Ad-MSCs might be a promising candidate in regulating inflammatory responses and in managing PD.

\section{Declarations}

\section{Ethics approval and consent to participate}

The procedures were approved by the Human Research Ethics Committee of our hospital (WYYY2014001) and written informed consent was obtained from all subjects.

\section{Consent for publication}

All participants and all authors agree to publish this manuscript.

\section{Availability of data and material}

All data and materials are available upon reasonable request to $\mathrm{Dr}$ Yong Bi.

\section{Competing interests}

The authors declare that there is no conflict of interests.

\section{Funding}

This study was supported by a grant from Commission of Health and Family Planning, Hongkou District, Shanghai, awarded to Dr Yong Bi (No.1701-02). a grant from Zhengjiang Natural Science Foundation (LY15H090019), a grant from Wenzhou Scientific Planning (Y20140684), and a grant from the State Key Open Projects of Soochow University (KJS1726).

\section{Authors' contributions}

YB, WC, XZ, SW and CL conceived and designed the study, YB, XL, HL, DY, XZ, JK, JX, ZC collected data and performed data analysis. $Y B$ and $X L$ wrote the draft of this manuscript. $H L, W C, S W, X Z$, and $C L$ edited the manuscript.

\section{Acknowledgements}

The authors thank the patients who donated their blood and adipose tissue.

\section{References}

1. Kalia LV, Lang AE. Parkinson's disease. Lancet. 2015;386(9996):896-912. 
2. Hughes AJ, Daniel SE, Kilford L, Lees AJ. Accuracy of clinical diagnosis of idiopathic Parkinson's disease: a clinico-pathological study of 100 cases. J Neurol Neurosurg Psychiatry. 1992;55(3):181-4.

3. Prinz $M$, Priller $J$. The role of peripheral immune cells in the CNS in steady state and disease. Nat Neurosci. 2017;20(2):136-144.

4. Brochard V, Combadière B, Prigent A, Laouar Y, Perrin A, Beray-Berthat V, Bonduelle $O$, Alvarez-Fischer D, Callebert J, Launay JM, Duyckaerts C, Flavell RA, Hirsch EC, Hunot S. Infiltration of CD4+ lymphocytes into the brain contributes to neurodegeneration in a mouse model of Parkinson disease. J. Clin. Invest. 2009;119(1):182-92.

5. Saunders JA, Estes KA, Kosloski LM, Allen HE, Dempsey KM, Torres-Russotto DR, Meza JL, Santamaria PM, Bertoni JM, Murman DL, Ali HH, Standaert DG, Mosley RL, Gendelman HE. CD4+ regulatory and effector/memory T cell subsets profile motor dysfunction in Parkinson's disease. $\mathrm{J}$ Neuroimmune Pharmacol. 2012;7(4):927-38.

6. Cen L, Yang C, Huang S, Zhou M, Tang X, Li K, Guo W, Wu Z, Mo M, Xiao Y, Chen X, Yang X, Huang Q, Chen C, Qu S, Xu P. Peripheral Lymphocyte Subsets as a Marker of Parkinson's Disease in a Chinese Population. Neurosci Bull. 2017;33(5):493-500.

7. Park J, Lee JW, Cooper SC, Broxmeyer HE, Cannon JR, Kim CH. Parkinson disease-associated LRRK2 G2019S transgene disrupts marrow myelopoiesis and peripheral Th17 response. J Leukoc Biol. 2017;102(4):1093-1102.

8. Sulzer D, Alcalay RN, Garretti F, Cote L, Kanter E, Agin-Liebes J, Liong C, McMurtrey C, Hildebrand WH, Mao X, Dawson VL, Dawson TM, Oseroff C, Pham J, Sidney J, Dillon MB, Carpenter C, Weiskopf D, Phillips E, Mallal S, Peters B, Frazier A, Lindestam Arlehamn CS, Sette A. T cells from patients with Parkinson's disease recognize a-synuclein peptides. Nature. 2017;546(7660):656-661.

9. Storelli E, Cassina N, Rasini E, Marino F, Cosentino M. Do Th17 Lymphocytes and IL-17 Contribute to Parkinson's Disease? A Systematic Review of Available Evidence. Front Neurol. 2019;10:13.

10. Sommer A, Marxreiter F, Krach F, Fadler T, Grosch J, Maroni M, Graef D, Eberhardt E, Riemenschneider MJ, Yeo GW, Kohl Z, Xiang W, Gage FH, Winkler J, Prots I, Winner B. Th17 Lymphocytes Induce Neuronal Cell Death in a Human iPSC-Based Model of Parkinson's Disease. Cell Stem Cell. 2018;23(1):123-131.e6.

11. Liu Z, Qiu AW, Huang Y, Yang Y, Chen JN, Gu TT, Cao BB, Qiu YH, Peng YP. IL-17A exacerbates neuroinflammation and neurodegeneration by activating microglia in rodent models of Parkinson's disease. Brain Behav Immun. 2019;81:630-645.

12. Reynolds AD, Stone DK, Hutter JA, Benner EJ, Mosley RL, Gendelman HE. Regulatory T cells Attenuate Th17 cell mediated nigrostriatal dopaminergic neurodegeneration in a model of Parkinson's disease. J. Immunol. 2010;184, 2261-71.

13. Liu Z, Huang Y, Cao BB, Qiu YH, Peng YP. Th17 Cells Induce Dopaminergic Neuronal Death via LFA1/ICAM-1 Interaction in a Mouse Model of Parkinson's Disease. Mol Neurobiol. 2017;54(10):77627776 . 
14. Dutta D, Kundu M, Mondal S, Roy A, Ruehl S, Hall DA, Pahan K. RANTES-induced invasion of Th17 cells into substantia nigra potentiates dopaminergic cell loss in MPTP mouse model of Parkinson's disease. Neurobiol Dis. 2019;132:104575.

15. Reynolds AD, Stone DK, Mosley RL, Gendelman HE. Proteomic studies of nitrated alpha-synuclein microglia regulation by CD4+CD25+T cells. J. Proteome Res. 2009; 8, 3497-511.

16. Huang Y, Liu Z, Cao BB, Qiu YH, Peng YP. Treg Cells Protect Dopaminergic Neurons against MPP+ Neurotoxicity via CD47-SIRPA Interaction. Cell Physiol Biochem. 2017;41(3): 1240-1254.

17. Duffy SS, Keating BA, Perera CJ, Moalem-Taylor G. The role of regulatory T cells in nervous system pathologies. J Neurosci Res. 2018;96(6):951-968.

18. Chen Y, Qi B, Xu W, Ma B, Li L, Chen Q, Qian W, Liu X, Qu H. Clinical correlation of peripheral CD4+-cell sub-sets, their imbalance and Parkinson's disease. Mol Med Rep. 2015;12(4):6105-11.

19. Álvarez-Luquín DD, Arce-Sillas A, Leyva-Hernández J, Sevilla-Reyes E, Boll MC, Montes-Moratilla E, Vivas-Almazán V, Pérez-Correa C, Rodríguez-Ortiz U, Espinoza-Cárdenas R, Fragoso G, Sciutto E, Adalid-Peralta L. Regulatory impairment in untreated Parkinson's disease is not restricted to Tregs: other regulatory populations are also involved. J Neuroinflammation. 2019;16(1):212.

20. Gendelman HE, Zhang Y, Santamaria P, Olson KE, Schutt CR, Bhatti D, Shetty BLD, Lu Y, Estes KA, Standaert DG, Heinrichs-Graham E, Larson L, Meza JL, Follett M, Forsberg E, Siuzdak G, Wilson TW, Peterson C, Mosley RL. Evaluation of the safety and immunomodulatory effects of sargramostim in a randomized, double-blind phase 1 clinical Parkinson's disease trial. NPJ Parkinsons Dis. 2017;3:10.

21. Zhu J, Yamane H, Paul WE. Differentiation of effector CD4 T cell populations. Annu Rev Immunol. 2010;28:445-89.

22. Littman DR, Rudensky AY. Th17 and regulatory T cells in mediating and restraining inflammation. Cell. 2010;140(6):845-58.

23. Weaver CT, Hatton RD. Interplay between the TH17 and TReg cell lineages: a (co-)evolutionary perspective. Nat Rev Immunol. 2009;9(12):883-9.

24. Bartlett HS, Million RP. Targeting the IL-17-T(H)17 pathway. Nat Rev Drug Discov. 2015;14(1):11-2.

25. Chang KA, Lee JH, Suh YH. Therapeutic potential of human adipose-derived stem cells in neurological disorders. J Pharmacol Sci. 2014;126(4):293-301.

26. Shi Y, Wang Y, Li Q, Liu K, Hou J, Shao C, Wang Y. Immunoregulatory mechanisms of mesenchymal stem and stromal cells in inflammatory diseases. Nat Rev Nephrol. 2018;14(8): 493-507.

27. Darlington PJ, Boivin MN, Renoux C, François M, Galipeau J, Freedman MS, Atkins HL, Cohen JA, Solchaga L, Bar-Or A. Reciprocal Th1 and Th17 regulation by mesenchymal stem cells: Implication for multiple sclerosis. Ann Neurol. 2010;68(4):540-5.

28. Álvaro-Gracia JM, Jover JA, García-Vicuña R, Carreño L, Alonso A, Marsal S, Blanco F, MartínezTaboada VM, Taylor P, Martín-Martín C, DelaRosa O, Tagarro I, Díaz-González F. Intravenous administration of expanded allogeneic adipose-derived mesenchymal stem cells in refractory rheumatoid arthritis (Cx611): results of a multicentre, dose escalation, randomised, single-blind, placebo-controlled phase Ib/lla clinical trial. Ann Rheum Dis. 2017;76(1):196-202. 
29. Wang D. Huang S. Yuan X. Liang J. Xu R. Yao G. Feng X. Sun L. The regulation of the Treg/Th17 balance by mesenchymal stem cells in human systemic lupus erythematosus. Cell Mol Immunol. 2017;14(5):423-431.

30. Panés J. García-Olmo D. Van Assche G. Colombel JF. Reinisch W. Baumgart DC. Dignass A. Nachury M. Ferrante M. Kazemi-Shirazi L. Grimaud JC. de la Portilla F. Goldin E. Richard MP. Leselbaum A. Danese S. ADMIRE CD Study Group Collaborators. Expanded allogeneic adipose-derived mesenchymal stem cells (Cx601) for complex perianal fistulas in Crohn's disease: a phase 3 randomised, double-blind controlled trial. Lancet. 2016;388(10051):1281-90.

31. Prots I, Winner B. Th17 cells: a promising therapeutic target for Parkinson's disease? Expert Opin Ther Targets. 2019;23(4):309-314.

32. Lin X, Chen Y, Yang DH, Xie YL, Bi Y, Ke JM, Chen ZB, Su ZQ, Li X, Zhang X. Adipose tissuederived stem cells mediated immunosuppression on Th17 in multiple sclerosis. Chinese Journal of Pathophysiology. 2016, 32(1):51-57.

33. Li J, Chen Y, Chen Z, Huang Y, Yang D, Su Z, Weng Y, Li X, Zhang X. Therapeutic effects of human adipose tissue-derived stem cell ( $\mathrm{hADSC}$ ) transplantation on experimental autoimmune encephalomyelitis (EAE) mice. Sci Rep. 2017;7:42695.

34. Cao W, Yang Y, Wang Z, Liu A, Fang L, Wu F, Hong J, Shi Y, Leung S, Dong C, Zhang JZ. Leukemia inhibitory factor inhibits $T$ helper 17 cell differentiation and confers treatment effects of neural progenitor cell therapy in autoimmune disease. Immunity. 2011;35(2):273-84.

35. Janssens K, Van den Haute C, Baekelandt V, Lucas S, van Horssen J, Somers V, Van Wijmeersch B, Stinissen P, Hendriks JJ, Slaets $\mathrm{H}$, Hellings $\mathrm{N}$. Leukemia inhibitory factor tips the immune balance towards regulatory T cells in multiple sclerosis. Brain Behav Immun. 2015;45:

36. Kalia LV, Kalia SK, Lang AE. Disease-modifying strategies for Parkinson's disease. Mov Disord. 2015;30(11):1442-50.

37. Athauda D, Foltynie T. The ongoing pursuit of neuroprotective therapies in Parkinson disease. Nat Rev Neurol. 2015;11(1):25-40.

38. Schutt CR, Gendelman HE, Mosley RL. Tolerogenic bone marrow-derived dendritic cells induce neuroprotective regulatory T cells in a model of Parkinson's disease. Mol Neurodegener. 2018;13(1):26.

39. Peters A, Pitcher LA, Sullivan JM, Mitsdoerffer M, Acton SE, Franz B, Wucherpfennig K, Turley S, Carroll MC, Sobel RA, Bettelli E, Kuchroo VK. Th17 cells induce ectopic lymphoid follicles in central nervous system tissue inflammation. Immunity. 2011;35(6):986-96.

40. Ghannam S, Pène J, Moquet-Torcy G, Jorgensen C, Yssel H. Mesenchymal stem cells inhibit human Th17 cell differentiation and function and induce a T regulatory cell phenotype. J Immunol. 2010;185(1):302-12.

41. Baharlou R, Ahmadi-Vasmehjani A, Faraji F, Atashzar MR, Khoubyari M, Ahi S, Erfanian S, Navabi SS. Human adipose tissue-derived mesenchymal stem cells in rheumatoid arthritis: Regulatory effects on peripheral blood mononuclear cells activation. Int Immunopharmacol. 2017;47:59-69. 
42. Kwon MS, Noh MY, Oh KW, Cho KA, Kang BY, Kim KS, Kim YS, Kim SH. The immunomodulatory effects of human mesenchymal stem cells on peripheral blood mononuclear cells in ALS patients. $J$ Neurochem. 2014;131(2):206-18

43. Singer NG, Caplan Al. Mesenchymal stem cells: mechanisms of inflammation. Annu Rev Pathol. 2011;6:457-78.

44. Metcalfe SM. LIF in the regulation of T-cell fate and as a potential therapeutic. Genes Immun. 2011;12(3):157-68.

45. Gao W, Thompson L, Zhou Q, Putheti P, Fahmy TM, Strom TB et al. Treg versus Th17 lymphocyte lineages are crossregulated by LIF versus IL-6. Cell Cycle 2009; 8: 1444-1450.

\section{Figures}




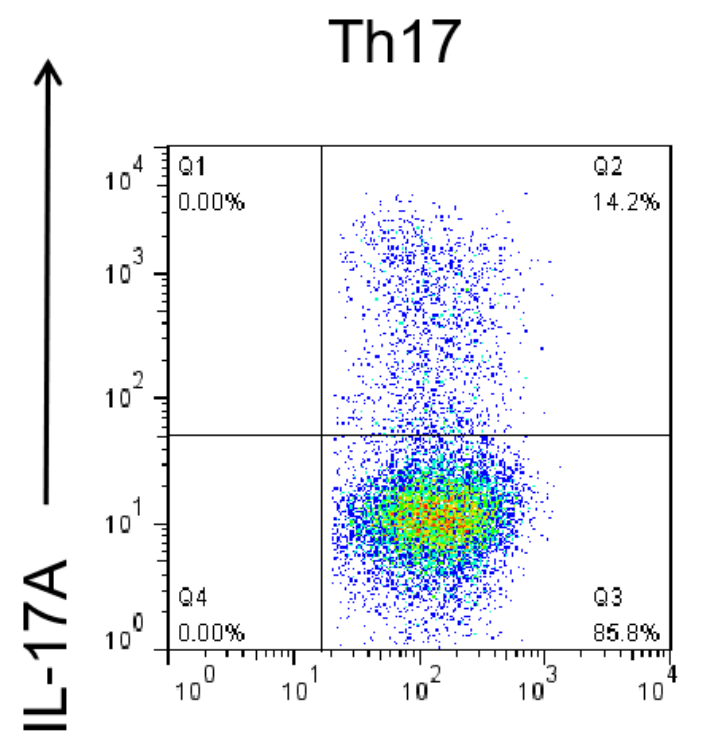

\section{Th17+AD-MSCs}

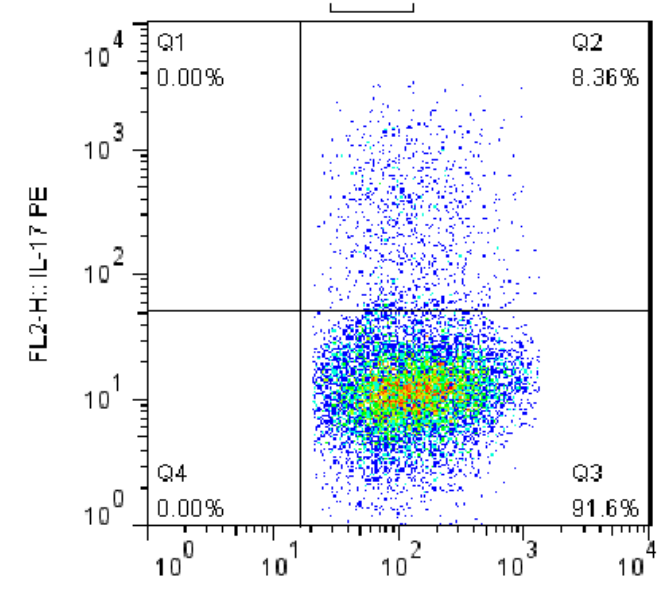

A CD4

Th17/CD4 ${ }^{+}$T Ratio

RORYt mRNA
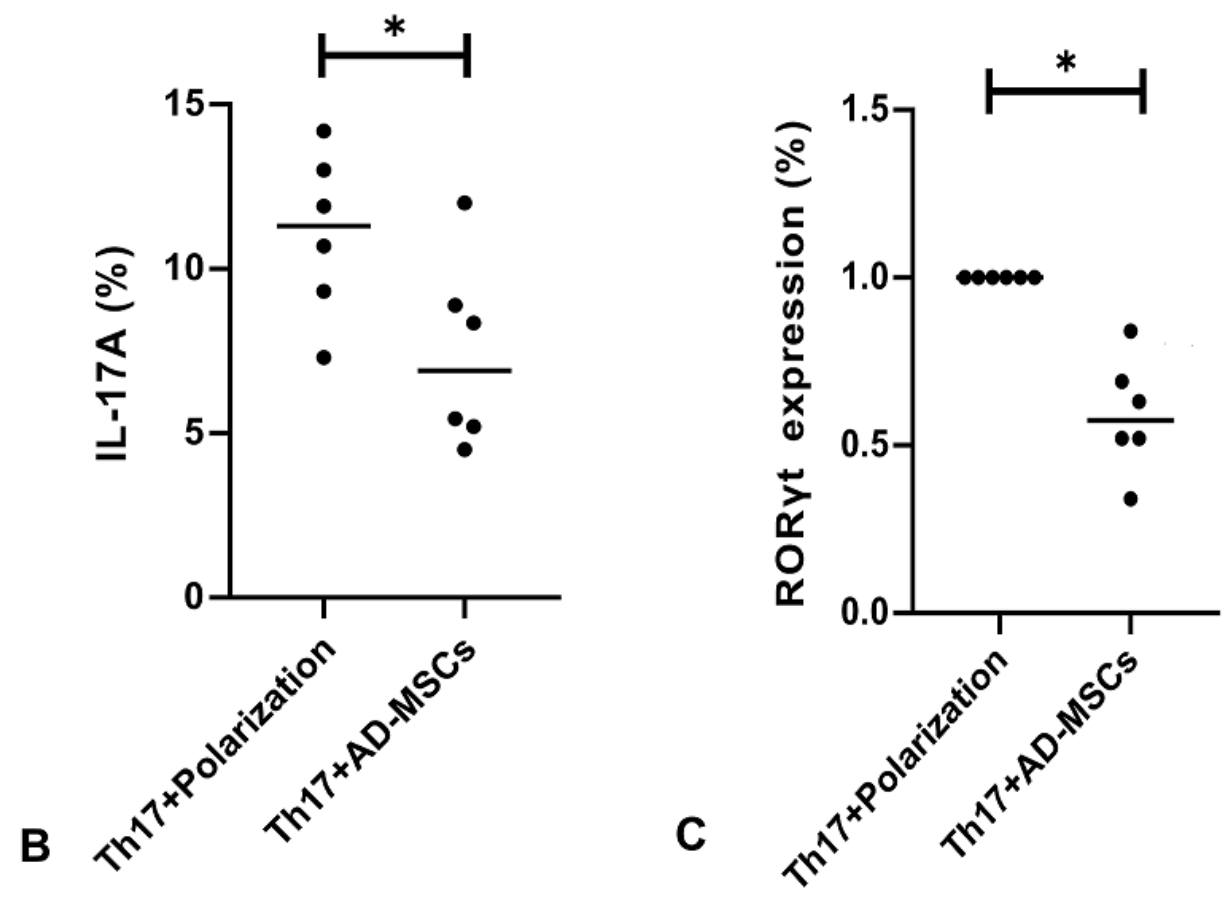

Figure 1

Ad-MSCs inhibited the differentiation of CD4+T cells into Th17 cells. Percentage of Th17 (IL-17A+CD4+) cells was analyzed by flow cytometry $(A, B)$. After $4 d$ co-culture with AD-MSCs, the level of RORyt mRNA was analyzed by real-time PCR (C). * $P<0.05$. 
IL-6R mRNA

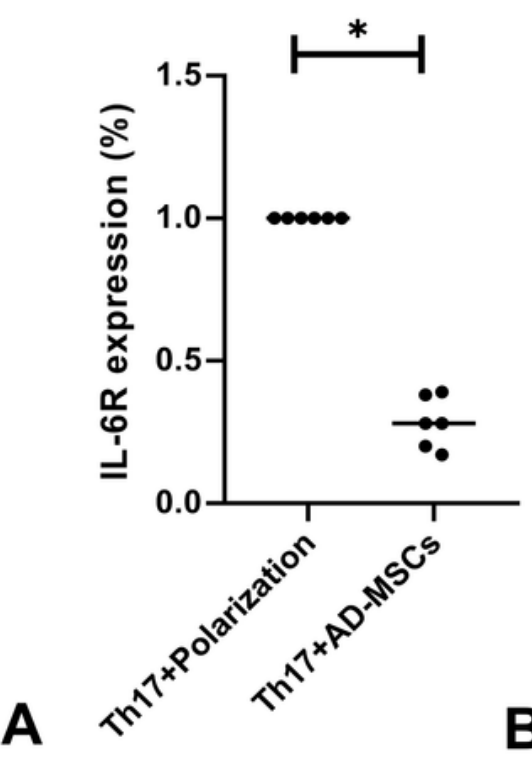

A

IL -6

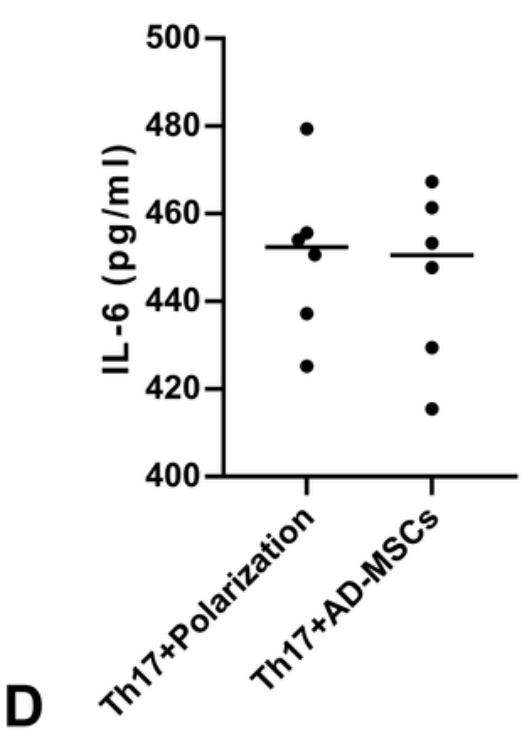

IL-23R mRNA

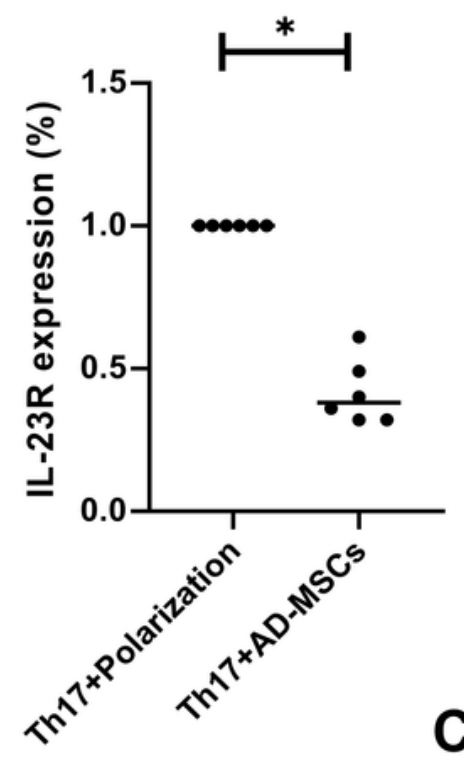

IL -23

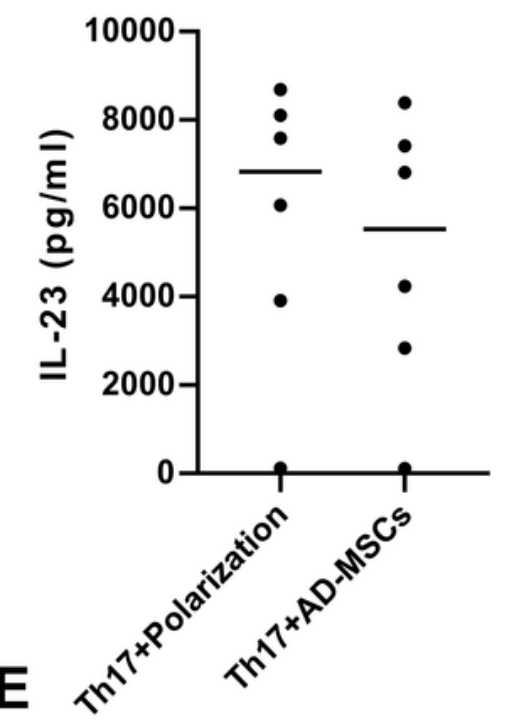

\section{IL-6R mRNA}

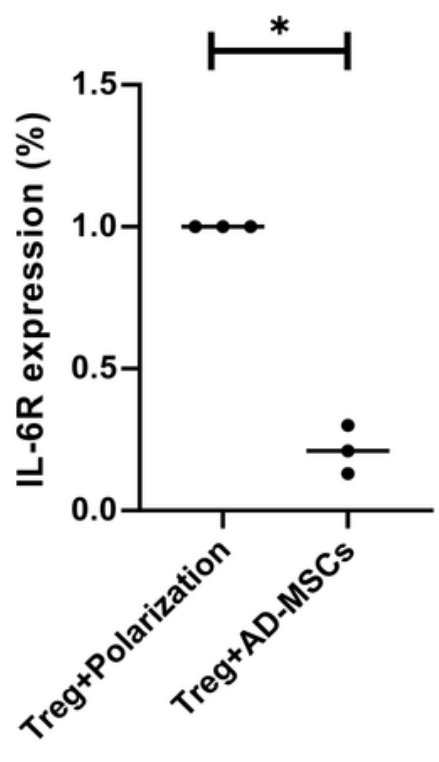

TGF- $\beta$

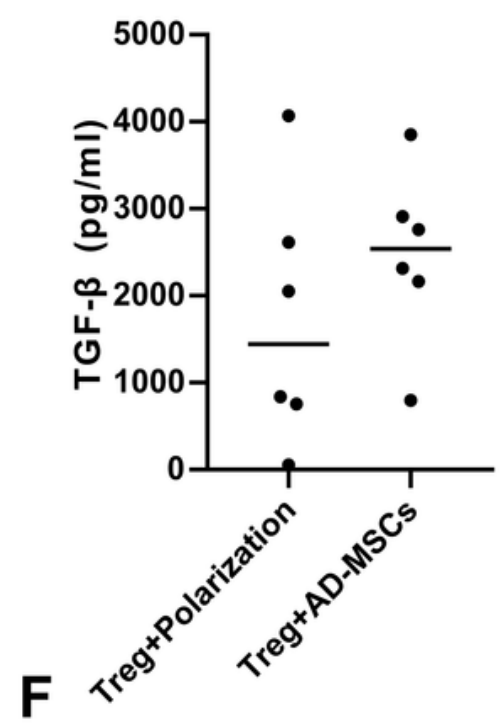

Figure 2

Ad-MSCs suppressed the expression of cytokines and their receptors. Decreased expression of IL-6R mRNA was observed in co-cultures than under either the Th17 or the Treg polarized condition (A, C), and decreased IL-23R mRNA under the Th17 polarized condition (B). Protein levels of IL-6, IL-23 and TGF- $\beta$ showed no significant change in the co-culture group than in the $\mathrm{CD} 4+\mathrm{T}$ cell group under either polarized condition (D-F). * $\mathrm{P}<0.05$. 


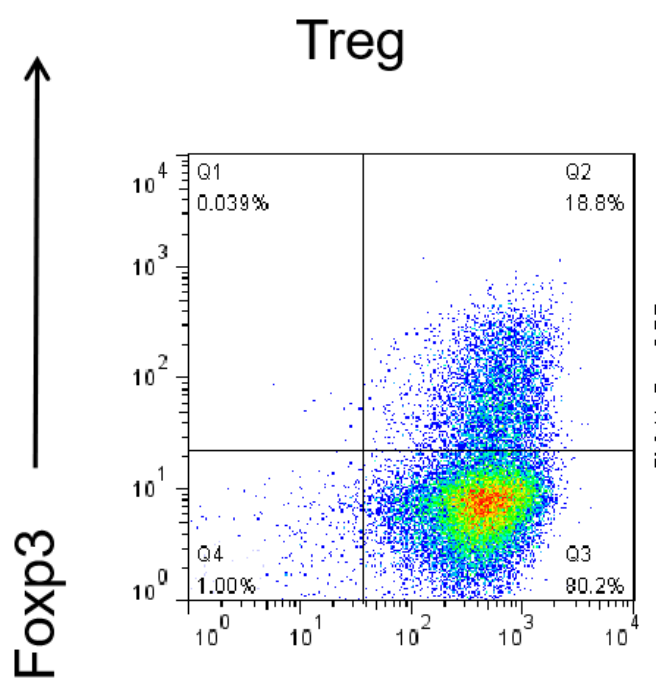

\section{Treg+AD-MSCs}

A CD4 CD25
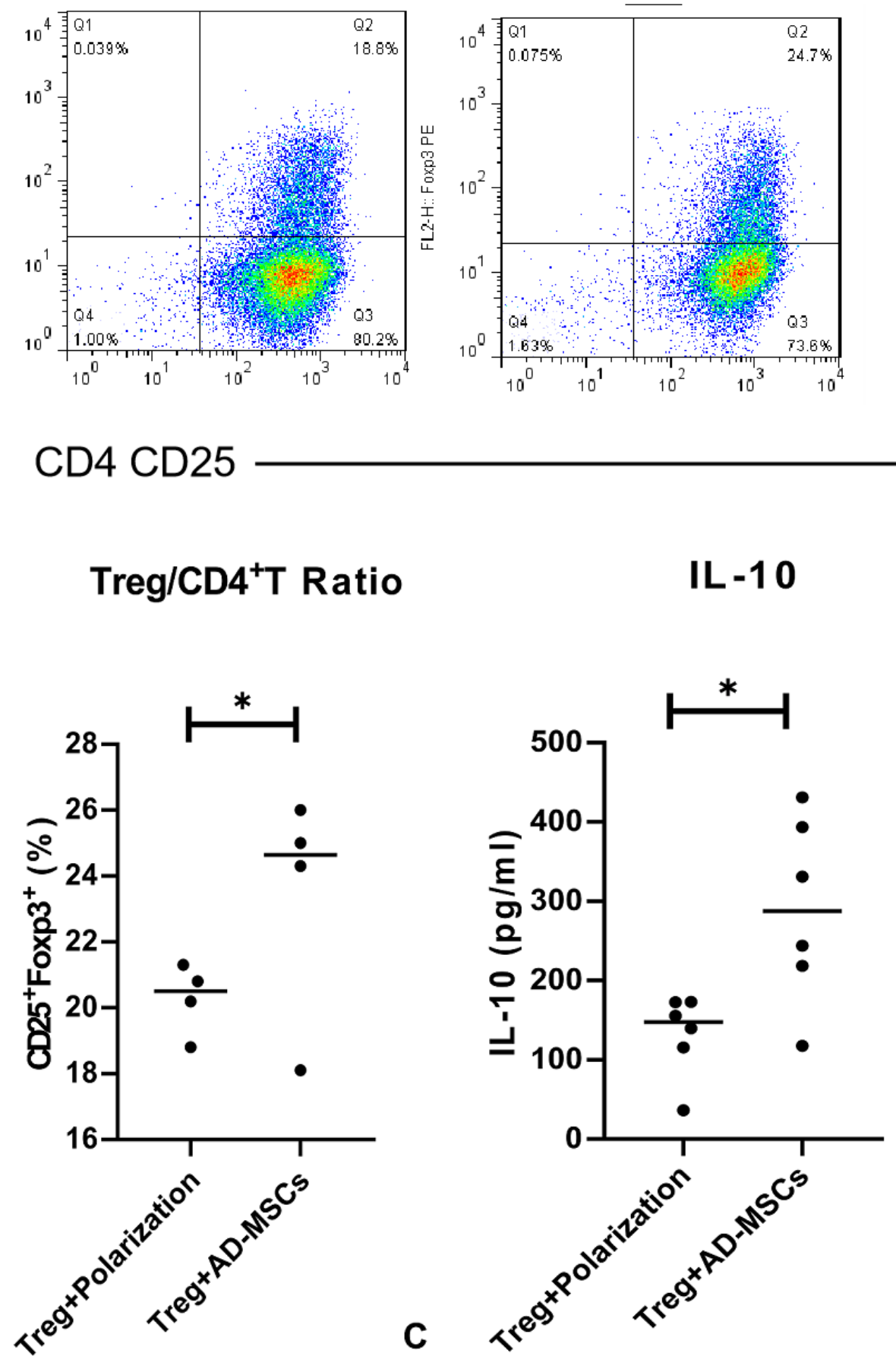

\section{Figure 3}

hAD-MSCs induced CD4+T cells to a functional Treg cell phenotype. Flow cytometry was used to analyze the proportion of Treg (CD4+CD25+Foxp3+T) cells (A). Increased level of IL-10 in the supernatant of cocultured system tested by ELISA $(B, C) .{ }^{*} P<0.05$. 
LIF Th17

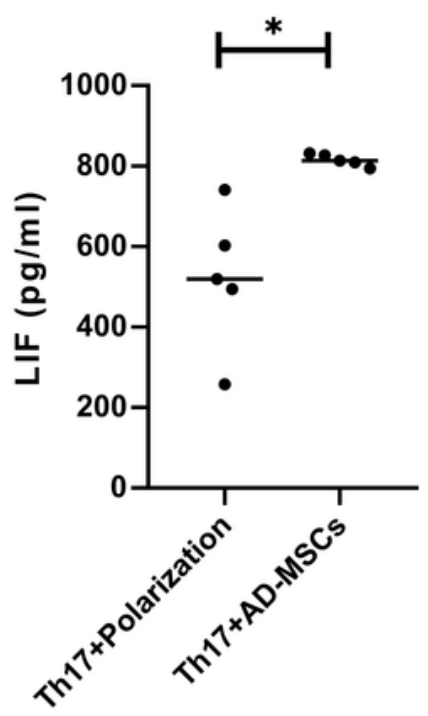

A

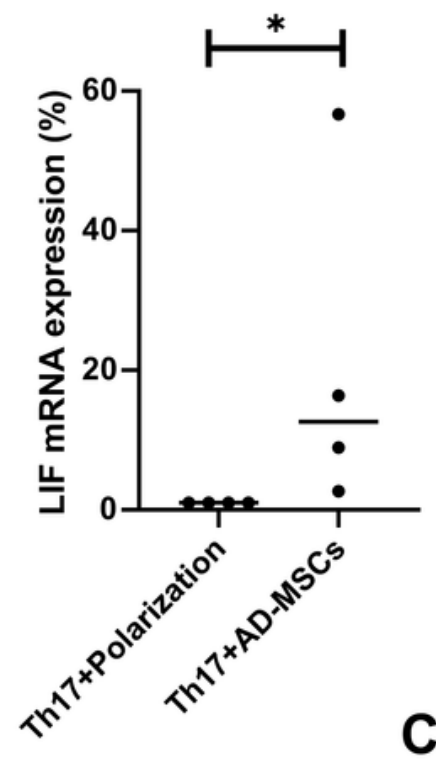

LIF mRNA Treg

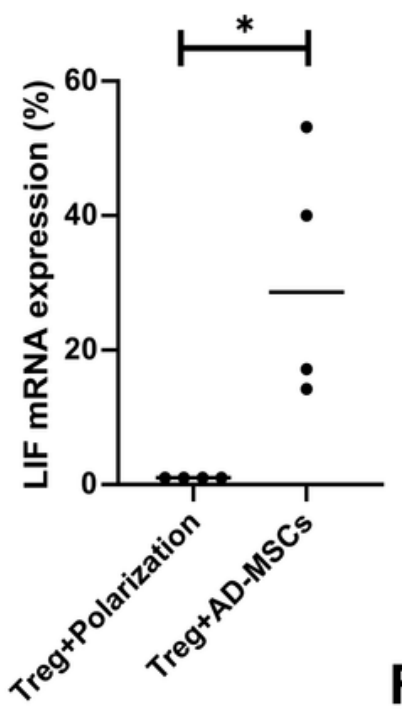

UFR mRNA Th17

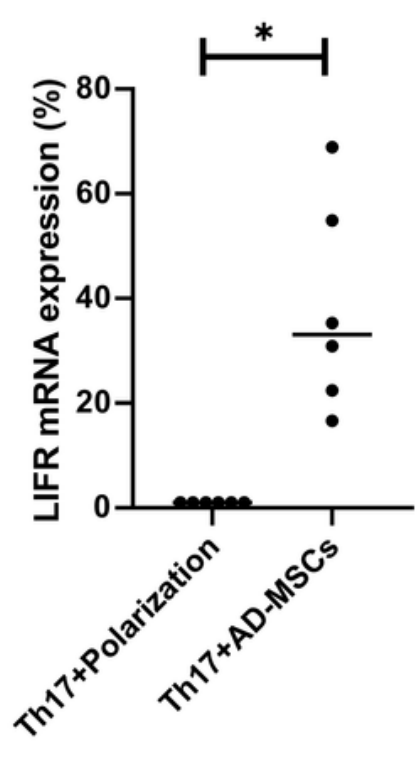

LIFR mRNA Treg

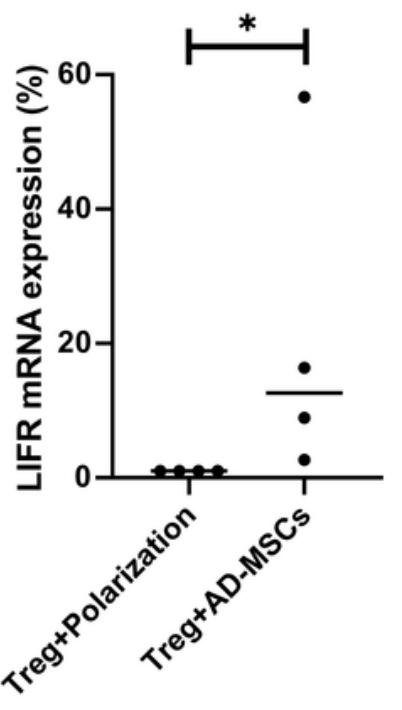

\section{Figure 4}

LIF is the key factor of the inhibitory effect. The level of LIF protein was significantly upregulated in the supernatant of the co-cultured system under either polarizing conditions tested by ELISA $(A, D)$, and increased expression of LIF mRNAs detected by Real-time PCR $(B, E)$. Expression of LIF-R mRNA was increased in co-cultures under both polarized conditions (C,F) as detected by Real-time PCR. * $P<0.05$. 